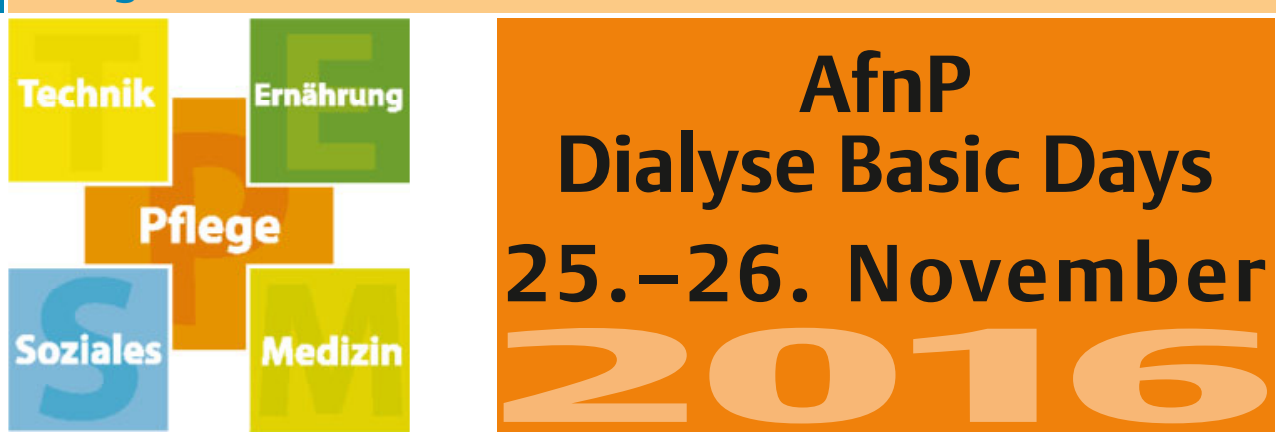

\title{
Der Verein für alle Berufsgruppen aus dem Arbeitsfeld Nephrologie
}

Die Arbeitsgemeinschaft

\section{für nephrologisches Personal e.V.}

Die 1979 gegründete AfnP ist mit über 1500 Mitgliedern der größte nationale Berufsverein für die nephrologische Pflege. Selbstverständlich finden auch andere Berufsgruppen aus dem Tätigkeitsfeld der Nephrologie und Nierenersatztherapie sowie verwandte Verfahren in der AfnP einen Ansprechpartner. In ihrer Vereinsgeschichte hat die AfnP wichtige Ziele erreicht und viele Anliegen ihrer Mitglieder realisiert.

Wir nehmen maßgeblichen Einfluss auf Veränderungen und Entwicklungen in der Nephrologie und Dialyse. Wir tun dies in Kooperation und im Dialog mit den ärztlichen Fachgesellschaften und gesellschaftlich relevanten Institutionen.

Wir transportieren Ideen unserer Mitglieder an die richtigen Adressen Stellvertretend für das Erreichte steht die Fachweiterbildung Fachkrankenpflege Nephrologie, an deren Implementierung die AfnP maßgeblich beteiligt war. Als Mitglied in der Bundesarbeitsgemeinschaft der nephrologischen Weiterbildungsstätten und in der Arbeitsgruppe der DKG (Deutsche Krankenhausgesell-

\section{Ti:}

\section{Arbeltsgemelnschaft für} nephrologisches Personal e.V.

Verantwortlich für die AfnP-Fachgesellschaftsseiten: Marion Bundschu, Ulm (V.i.S.d.P.)

So können Sie uns erreichen:

AfnP-Geschäftsstelle

Käppelesweg 8, 89129 Langenau

Tel.: 07345/22933, Fax: 0 7345/7540

E-Mail: info@afnp.de, Internet: www.afnp.de

Vorstand der AfnP:

- Marion Bundschu (1. Vorsitzende)

- Hans-Martin Schröder (stellv. Vorsitzender)

- Roswitha Nicklas (Schatzmeisterin)

- Ilona Adler (Schriftführerin)

\section{Steckbrief}

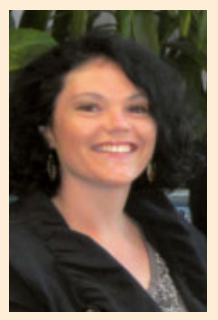

Rebecca Fiedler

Beruflicher Werdegang

Erster Kontakt zur AfnP

Aufgabengebiete in der AfnP

- Ländervertreterin Hessen

Der Rest meiner Zeit gehört ... schaft) wird diese Arbeit energisch fortgesetzt. Neben zahlreichen weiteren Projekten erarbeiten wir gemeinsam mit dem Arbeitskreis für angewandte Hygiene die „Leitlinie für angewandte Hygiene in Dialyseeinheiten“.

\section{Zahlreiche Vorteile als Mitglied} Als Mitglied (Jahresbeitrag seit dem 01.01.2015: 30 Euro) erhalten Sie einen Bildungsgutschein im Wert von 40 Euro (einzulösen bei allen AfnP-Veranstaltun-

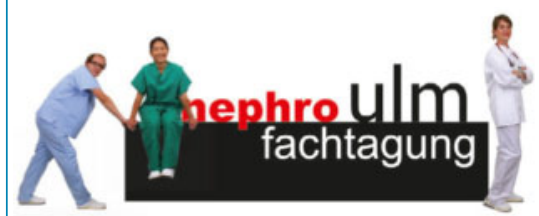

10. und 11. März 2017, Ulm

gen) und bis zu 10-mal jährlich die Zeitschrift Dialyse aktuell. In ungeraden Jahren finden im November das AfnP-Symposium bzw. in geraden Jahren die Dialyse Basic Days und jährlich im März die Nephro Fachtagung Ulm statt. Auch bieten wir regionale Fortbildungsveranstaltungen an. Unsere Länder- oder Arbeitsgruppenvertreter stehen Ihnen für Fragen und Anregungen gerne zur Verfügung. Die Adressen und weitere Informationen erhalten Sie über die Geschäftsstelle oder unsere Internetpräsenz. Im mitgliedergeschützten Bereich auf www. afnp.de (Login über 5-stellige MitgliedNr. und den Namen) können Sie auf aktuelle AfnP-Informationen und Artikel aus der Dialyse aktuell zugreifen. Ihre AfnP

geboren 1979, wohnhaft in Fulda

- seit 01.06.2000 in der Dialysestation des Klinikums Fulda

- 2006-2007 Weiterbildung zur Praxisanleitung

- 2011-2013 Weiterbildung zur Fachkrankenschwester für Nephrologie und Dialyse

- 2011 durch Frau Bundschu während meiner nephrologischen Fachweiterbildung

... meiner Familie, meinen Freunden und meinen Hobbys. 